\title{
Suprasellar and recurrent pediatric craniopharyngiomas: expanding indications for the extended endoscopic transsphenoidal approach
}

\author{
Andrew F. Alalade, MBBS, FRCS(SN), ${ }^{1}$ Elizabeth Ogando-Rivas, MD,1 Jerome Boatey, MD, ${ }^{1}$ \\ Mark M. Souweidane, MD, ${ }^{1}$ Vijay K. Anand, MD, ${ }^{2}$ Jeffrey P. Greenfield, MD, PhD, ${ }^{1}$ and \\ Theodore H. Schwartz, MD'-3 \\ Departments of ${ }^{1}$ Neurosurgery, ${ }^{2}$ Otolaryngology, and ${ }^{3}$ Neuroscience, Weill Cornell Medical College, NewYork-Presbyterian, \\ New York, New York
}

\begin{abstract}
OBJECTIVE The expanded endonasal endoscopic transsphenoidal approach has become increasingly used for craniopharyngioma surgery in the pediatric population, but questions still persist regarding its utility in younger children, in recurrent and irradiated tumors, and in masses primarily located in the suprasellar region. The narrow corridor, incomplete pneumatization, and fear of hypothalamic injury have traditionally relegated this approach to application in older children with mostly cystic craniopharyngiomas centered in the sella. The authors present a series of consecutive pediatric patients in whom the endonasal endoscopic approach was used to remove craniopharyngiomas from patients of varied ages, regardless of the location of the tumor and previous treatments or surgeries, to ascertain if the traditional concerns about limitations of this approach are worth reevaluating
\end{abstract}

METHODS Eleven consecutive pediatric patients (age $\leq 18$ years) underwent surgery via an endoscopic transsphenoidal approach at NewYork-Presbyterian/Weill Cornell Medical Center from 2007 to 2016. The authors recorded the location, consistency, and size of the lesion, assessed for hypothalamic invasion radiographically, calculated skull base measurements, and assessed parameters such as extent of resection, visual function, endocrinological function, weight gain, and return-to-school status.

RESULTS The average age at the time of surgery was 7.9 years (range 4-17 years) and the tumor sizes ranged from 1.3 to $41.7 \mathrm{~cm}^{3}$. Five cases were purely suprasellar, 5 had solid components, 4 were reoperations, and 5 had a conchal sphenoid aeration. Nevertheless, gross-total resection was achieved in $45 \%$ of the patients and $50 \%$ of those in whom it was the goal of surgery, without any correlation with the location, tumor consistency, or the age of the patient. Neartotal resection, subtotal resection, or biopsy was performed intentionally in the remaining patients to avoid hypothalamic injury. Anterior pituitary dysfunction occurred in $81.8 \%$ of the patients, and $63.3 \%$ developed diabetes insipidus . Two patients (18\%) had a greater than $9 \%$ increase in body mass index. Visual function was stable or improved in $73 \%$. All children returned to an academic environment, with 10 of them in the grade appropriate for their age. There was a single case of each of the following: CSF leak, loss of vision unilaterally, and abscess.

CONCLUSIONS The endoscopic transsphenoidal approach is suitable for removing pediatric craniopharyngiomas even in young children with suprasellar tumors, conchal sphenoid sinus, recurrent tumors, and tumors with solid components. The extent of resection is dictated by intrinsic hypothalamic tumor invasiveness rather than the approach. The endoscopic transsphenoidal approach affords the ability to directly inspect the hypothalamus to determine invasion, which may help spare the patient from hypothalamic injury. Irrespective of approach, the rates of postoperative endocrinopathy remain high and the learning curve for the approach to a relatively rare tumor is steep.

https://thejns.org/doi/abs/10.3171/2017.7.PEDS17295

KEY WORDS children; craniopharyngioma; endonasal; endoscopic; pediatric; minimally invasive; minimal access; skull base; transsphenoidal; pituitary surgery

ABBREVIATIONS BMI = body mass index; $\mathrm{CPC}=$ chiasm-pituitary corridor; $\mathrm{DI}=$ diabetes insipidus; $\mathrm{EEA}=$ endonasal endoscopic approach; $\mathrm{GTR}=$ gross-total resection; NTR = near-total resection; STR = subtotal resection

SUBMITTED June 5, 2017. ACCEPTED July 19, 2017.

INCLUDE WHEN CITING Published online November 10, 2017; DOI: 10.3171/2017.7.PEDS17295. 
$\mathrm{C}$ RANIOPHARYNGIOMA is a rare benign tumor originating from Rathke's pouch, with a bimodal age distribution of 5-14 years and 50-75 years., , $^{8,63}$ Pediatric craniopharyngioma has an annual incidence of 5.25 per million and accounts for $6 \%-13 \%$ of all pediatric intracranial tumors. ${ }^{1,44}$ The lesion is histologically benign but, due to its proximity to the critical neurovascular and hypothalamopituitary axis structures, it poses challenges to the treating physician. ${ }^{1,61}$ Surgical or adjuvant treatment strategies in this eloquent location may have devastating effects, especially in the pediatric population in whom hypothalamic injury can result in the development of morbid obesity and cognitive decline. ${ }^{21}$ Almost all pediatric craniopharyngiomas are of the adamantinomatous type with a $C T N N B 1$ mutation, and they are generally calcified and thus not only more difficult to resect but also not responsive to medical therapy. ${ }^{20,44,63}$

The optimal management of craniopharyngiomas has been debated for decades..$^{12,40,49}$ In the past, transcranial surgery was generally recommended to achieve grosstotal resection (GTR) with the aim of surgical cure. ${ }^{12,29}$, 30,49 Surgery for childhood craniopharyngiomas, however, is associated with a perioperative mortality rate risk ranging from $0 \%$ to $16 \%,{ }^{19,41}$ neurological morbidity rate risk of 0\%-20\%, ${ }^{19}$ and pituitary-related endocrinopathy risk of up to $100 \% .{ }^{15}$ Hypothalamic obesity has been reported in as many as $70 \%$ of patients. ${ }^{4}$

The relatively high morbidity associated with GTR prompted neurosurgeons to seek alternatives, such as subtotal resection (STR) of the tumor or cyst fenestration with adjuvant radiotherapy. ${ }^{1,10,11,12,49}$ Intracystic bleomycin, interferon, and radioactive agents have also been administered in an attempt at reducing the recurrence risk.,12,62 Recently, $B R A F$ inhibitors have been demonstrated to show effectiveness against the $B R A F$-mutated papillary craniopharyngiomas. Unfortunately, almost all pediatric craniopharyngiomas are CTNNB1-mutated adamantinomatous type. For primarily sellar tumors, microscopic transsphenoidal resection has also been reported..$^{25,37}$ In recent years, the extended endonasal endoscopic approach (EEA) has been advocated for suprasellar craniopharyngiomas. ${ }^{3,13,17,32,36,42,51}$ Evidence to date has shown that, in comparison with the transcranial approach, endonasal endoscopic resection can result in better vision outcomes, higher GTR rate, and stable quality of life and comparable complication rates. . $3,27,31,51,56$ This technique has become arguably the preferred approach in the treatment of craniopharyngiomas.

In spite of the popularity of the EEA for adults, few reports exist of its use for pediatric craniopharyngiomas. ${ }^{1,2,50,51}$ Characteristic anatomical features such as the small nostrils and absent pneumatization of the sphenoidal sinus in the pediatric patients pose unique challenges to endoscopic neurosurgeons. ${ }^{2,50}$ On the other hand, the shorter distance between the nostril and sellar area (naresellar distance) facilitates endonasal endoscopic surgery. ${ }^{31}$ To study this developing technique and its application to the pediatric population, we reviewed the records of all patients $\leq 18$ years of age with craniopharyngiomas who underwent endonasal endoscopic resection at our institution.

\section{Methods}

Following approval from the IRB, we performed a retrospective review of a prospectively maintained database of all endonasal endoscopic surgeries performed in the Department of Neurological Surgery at Weill Cornell Medicine from 2009 to 2017. All pediatric patients (age $\leq 18$ years) with craniopharyngiomas treated via the EEA were identified. All patients had undergone pre- and postoperative neurological, otorhinolaryngological, ophthalmological, and endocrinological evaluation, general blood tests, hormone laboratory tests, and brain MRI. Tumor location was evaluated based on the sellar cavity, pituitary stalk, or extension into adjacent regions. Intraoperative parameters, anatomical measurements, extent of resection, complications, and follow-up duration were also recorded. The degree of resection was determined by a neuroradiologist examining the postoperative MR images and categorized as GTR (100\% removal), near-total resection (NTR) (>95\% removal), STR (<95\% removal), or biopsy $(>50 \%$ removal). The definition of NTR was created for cases in which the neuroradiologist noted thin linear enhancement on the floor of the hypothalamus but would definitely call this residual tumor. In these cases, the surgeon did not appreciate any residual tumor upon direct inspection of the floor of the hypothalamus. The regrowth potential of this residual tumor is unknown.

\section{Radiological Measurements}

Several measurement parameters were reviewed from the preoperative radiological images-that is, intercarotid distance at the level of the anterior clinoid processes, chiasm-pituitary corridor (CPC), nare-sellar distance, rostrocaudal diameter of the tumor, widest diameter of the tumor on coronal images, anteroposterior diameter of the tumor, and tumor volume. The CPC is measured as the maximal distance between the pituitary gland and optic chiasm on coronal sections, while the nare-sellar distance is the maximal distance on midsagittal sections, from the entrance of the nare to the most anterior point of the sellar rostrum.

\section{Anatomical Features}

Sellar pneumatization was described on the sagittal $\mathrm{MRI} / \mathrm{CT}$ slices and categorized as either presellar, sellar, postsellar, or conchal. ${ }^{55,58} \mathrm{~T} 1$-weighted (noncontrast and contrast-enhanced) and T2-weighted MR images were carefully reviewed to document the features of the tumor and the lesions were described as solid, cystic, and mixed. We classified a tumor as cystic if more than $50 \%$ of the tumor was cystic. This was corroborated by intraoperative examination and macroscopic analysis. The effects of the lesion on contiguous anatomical vital structures were also recorded, such as hypothalamic involvement and internal carotid artery encasement. Hypothalamic involvement was based on either increased signal in the hypothalamus demonstrated on FLAIR images or deformation of the hypothalamus by the top of the tumor. The hypothalamic region was defined as the region between the lamina terminalis and optic chiasm anteriorly to the mammillary bodies posteriorly, as shown on the sagittal 
MRI sequences. A line drawn from the anterior commissure to the posterior commissure formed the superior border, with the floor formed by the tuber cinereum, median eminence, and pituitary stalk. Our philosophy with regard to surgical goals is to try to achieve a GTR for all tumors without hypothalamic involvement and to debulk as much of the tumor as can be safely removed for those that involve the hypothalamus.

\section{Surgical Procedure}

The surgical approach was similar in all cases and consisted of a purely EEA. The details of this approach are well documented elsewhere but some of the specifics that pertain to pediatric patients or that are unique to our institution are highlighted here. . $^{35,36,42}$ MRI-based navigation is used in all cases with CTA navigation coregistered in selective cases. CTA was particularly helpful when the sphenoid sinus was not yet fully pneumatized and required extensive drilling. General anesthesia was induced, and the patient was given vancomycin $(15 \mathrm{mg} / \mathrm{kg})$ and ceftazidime $(50 \mathrm{mg} / \mathrm{kg})$, steroids, and antihistamines. A lumbar drain was placed, and $0.2 \mathrm{ml}$ of $10 \%$ fluorescein (AK-Fluor, AKORN) was mixed in $10 \mathrm{ml}$ of CSF before infusion to help visualize any possible CSF leaks. ${ }^{46-48,57} \mathrm{~A}$ nasoseptal flap was harvested. Any conchal bone in the sphenoid sinus was removed with a diamond drill down to hard cancellous bone. ${ }^{39,45}$ The bone opening varied based on the location of the tumor. For sellar tumors, the entire sella was opened, and if there was extension into the suprasellar cistern, the opening was extended up to the top of the tuberculum sella. ${ }^{33,38,40,52}$ For suprasellar tumors without sellar involvement, the opening consisted only of the top of the sella and tuberculum sella and the lateral limits were the medial opticocarotid recesses. ${ }^{53}$ The superior intercavenous sinus was cauterized and transected, and the dura was opened to the bone edge. For sellar tumors, these were internally decompressed and dissected free from the surrounding normal pituitary gland and stalk. If the goal of surgery was cure, and the gland and/or stalk were infiltrated, they were sacrificed. For suprasellar tumors, the corridor for surgery was above the pituitary gland and below the chiasm. The superior hypophyseal arteries were preserved if possible as was the stalk. The tumor was internally decompressed and then dissected free laterally and inferiorly. If the goal of surgery was cure, the tumor was then dissected free superiorly from the back of the chiasm and roof of the third ventricle. If the child was younger than 16 years and the tumor infiltrated the floor of the third ventricle, then residual tumor was purposefully left behind to avoid damage to the hypothalamus.

The dura was repaired with a gasket seal. ${ }^{22,35}$ This involved an on-lay of fascia lata held in place with a wedged piece of MEDPOR. In some cases, ALLODERM was used as a graft, and vomer was used as a buttress. The gasket was covered with a nasoseptal flap, which itself was covered with DuraSeal and then Floseal.

\section{Results \\ Demographics}

Eleven patients were included in the study. Their mean age at the time of surgery was 7.9 years (range 4-17 years). Eight of the patients were male. The histological diagnosis was adamantinomatous (WHO Grade I) in all 11 cases.

\section{Clinical Presentation}

Table 1 summarizes the clinical presentation, tumor characteristics, and history of related surgical procedures. The most common presenting symptom was visual impairment $(n=6)$ followed by growth retardation $(n=5)$. Four patients presented with headaches, 2 with somnolence/lethargy, 1 with cognitive impairment, and 1 with polyuria. Weight gain was also noted in one patient, and weight loss in another. Four patients $(37 \%)$ had prior surgery-intraventricular endoscopic biopsies in 2 patients and craniotomies for debulking or cyst fenestration in 2 patients.

\section{Preoperative Imaging}

Tumor volumes ranged from 1.3 to $41.7 \mathrm{~cm}^{3}$. Sphenoid sinuses were conchal $(\mathrm{n}=5)$, presellar $(\mathrm{n}=4)$ and sellar $(n=2)$. The intercarotid distance at the level of the anterior clinoid processes ranged from $11.06 \mathrm{~mm}$ to $25.6 \mathrm{~mm}$ (mean $14.63 \mathrm{~mm}$ ). An important step in this approach was traversing the corridor between the pituitary gland and the optic chiasm. This CPC distance ranged from $3.6 \mathrm{~mm}$ to $41 \mathrm{~mm}$ (mean $10.8 \mathrm{~mm}$ ). The nare-sellar distance ranged from 56.7 to $92.6 \mathrm{~mm}$ (mean $73.2 \mathrm{~mm}$ ).

Elevation of the floor of the hypothalamus was noted in 8 patients. In 7 of these 8 , there was imaging evidence of invasion defined as FLAIR signal in the hypothalamus. No internal carotid artery encasement was noted in any of the cases. Five cases were suprasellar/sellar, 5 were purely suprasellar (Fig. 1), and 1 was purely sellar. Five cases were mixed solid and cystic and 6 were predominantly cystic.

\section{Surgical Outcome}

Table 2 summarizes the extent of resection, as well as some of the outcomes. Five (45\%) patients had a GTR, 2 (18\%) had an NTR, and $3(27 \%)$ had an STR. The goal of surgery in 10 of 11 patients was to achieve a GTR. An STR was planned preoperatively for one of the patients. One patient (Case 8) with a predominantly cystic tumor received an intentional biopsy with partial debulking for optic chiasmal decompression. This was discussed with the patient and family prior to the procedure. For patients in whom GTR was the goal of surgery, this was achieved in $50 \%$ (Fig. 2).

In the 4 patients in whom the EEA procedure was a reoperation for tumor recurrence, there were 2 GTRs (50\%), 1 NTR, and 1 STR. For the patients with sellar involvement, GTR was achieved in 50\% of the cases and for the cases that were purely suprasellar GTR was also achieved in $50 \%$ of the cases. GTR was achieved in all $3(100 \%)$ of the patients without preoperative imaging-documented hypothalamic involvement in whom GTR was the goal. GTR was achieved in $2(28.6 \%)$ of the 7 patients with preoperative imaging-documented hypothalamic involvement following intraoperative assessment of an acceptable plane of dissection. Examining the role of solid versus 
TABLE 1. Clinical presentation, tumor characteristics, and history of surgical intervention

\begin{tabular}{|c|c|c|c|c|c|c|c|c|}
\hline \multirow{2}{*}{$\begin{array}{l}\text { Case } \\
\text { No. }\end{array}$} & \multirow{2}{*}{$\begin{array}{l}\text { Age } \\
\text { (yrs), } \\
\text { Sex }\end{array}$} & \multirow[b]{2}{*}{ Clinical Presentation } & \multirow[b]{2}{*}{ Previous Intervention } & \multirow[b]{2}{*}{ Location/ Consistency } & \multicolumn{3}{|c|}{ Measurements (mm) } & \multirow{2}{*}{$\begin{array}{c}\text { Sellar } \\
\text { Pneumatization }\end{array}$} \\
\hline & & & & & NSD & $I C D$ & $\mathrm{CPC}$ & \\
\hline 1 & $4, M$ & Visual impairment, HA & $\begin{array}{l}\text { Endoscopic biopsy \& } \\
\text { cyst decompression }\end{array}$ & $\begin{array}{l}\text { Sellar/suprasellar/intraventricular/transin- } \\
\text { fundibular + mixed }\end{array}$ & 56.7 & 13.1 & 5.2 & Conchal \\
\hline 2 & $5, M$ & Visual impairment & None & Sellar/suprasellar/intraventricular + cystic & NA & 13 & 25.9 & Presellar \\
\hline 3 & $4, M$ & $\begin{array}{l}\text { Cognitive impairment, } \\
\text { HA, lethargy }\end{array}$ & None & $\begin{array}{l}\text { Suprasellar/intraventricular/transinfundibu- } \\
\text { lar + cystic }\end{array}$ & 65.0 & 11.1 & 6.1 & Presellar \\
\hline 4 & $7, M$ & $\begin{array}{l}\text { Weight gain, growth } \\
\text { retardation, polyuria }\end{array}$ & None & $\begin{array}{l}\text { Suprasellar/intraventricular/transinfundibu- } \\
\text { lar + mixed }\end{array}$ & 70.6 & 15 & 3.6 & Conchal \\
\hline 5 & $8, M$ & $\begin{array}{l}\text { Visual impairment, } \\
\text { HA, somnolence }\end{array}$ & $\begin{array}{l}\text { Stereotactic endoscopic } \\
\text { cyst fenestration }\end{array}$ & $\begin{array}{l}\text { Suprasellar/intraventricular/transinfundibu- } \\
\text { lar + mixed }\end{array}$ & 79.7 & 14.2 & 6.0 & Presellar \\
\hline 6 & $9, F$ & Growth retardation & None & $\begin{array}{l}\text { Sellar/suprasellar/intraventricular/transin- } \\
\text { fundibular + cystic }\end{array}$ & 66.9 & 13.9 & 4.0 & Conchal \\
\hline 7 & $11, \mathrm{M}$ & Growth retardation & None & Sellar/retroinfundibular + cystic & NA & 12.9 & NA & Conchal \\
\hline 8 & $14, \mathrm{~F}$ & Growth retardation & None & $\begin{array}{l}\text { Suprasellar/intraventricular/transinfundibu- } \\
\text { lar + cystic }\end{array}$ & 75.4 & 10.2 & 4.0 & Sellar \\
\hline 9 & $9, M$ & $\begin{array}{l}\text { Growth retardation, } \\
\text { visual impairment }\end{array}$ & Transcranial debulking & Sellar/suprasellar/intraventricular + mixed & 70.2 & 25.6 & 41.7 & Conchal \\
\hline 10 & $14, \mathrm{~F}$ & Visual impairment, HA & Transsphenoidal biopsy & Sellar/suprasellar/transinfundibular + cystic & 82.3 & 15.8 & 5.9 & Sellar \\
\hline 11 & $17, M$ & $\begin{array}{l}\text { Visual impairment, } \\
\text { weight loss, HA }\end{array}$ & $\begin{array}{l}\text { Procedure attempted \& } \\
\text { cancelled due to re- } \\
\text { fractory hypertension }\end{array}$ & Suprasellar/transinfundibular + mixed & 92.6 & 16.13 & 6.3 & Sellar \\
\hline
\end{tabular}

$\mathrm{HA}=$ headache; ICD = intercarotid distance; NA = not applicable; NSD = nare-sellar distance.

cystic tumors, GTR was achieved in $40 \%$ of tumors with a mixed solid-cystic consistency and in $50 \%$ of tumors that were mostly cystic.

The majority of the patients were followed for more than 36 months. Follow-up duration for 4 patients (Cases $1,6,9$, and 10) was less than 36 months. These cases were omitted from the calculation of recurrence rates.

\section{Endocrine and Visual Outcomes}

Most of the patients presented with endocrine abnormalities preoperatively (72\%). Postoperatively, anterior pituitary function was worse in $81.8 \%$ (9 of 11) and posterior pituitary function was worse in $63.6 \%$ (7/11) compared with the preoperative status. There was no change in 1 patient who already had panhypopituitarism. Of the patients who presented with normal hypothalamic-pituitary function or partial hypopituitarism, new-onset hypopituitarism developed in 6 of 10 patients (Table 3). New thyroid dysfunction was noted in 5 of these patients and new growth hormone dysfunction in 1 patient.

At latest follow-up, 8 patients continued to take at least 3 hormonal supplementation medications. New-onset permanent diabetes insipidus (DI) developed in $6(54 \%)$ of 11 patients and transient DI occurred in 1 patient. The rate of new-onset permanent DI in patients who underwent firsttime surgery for resection was $43 \%$ (3 of 7 cases).
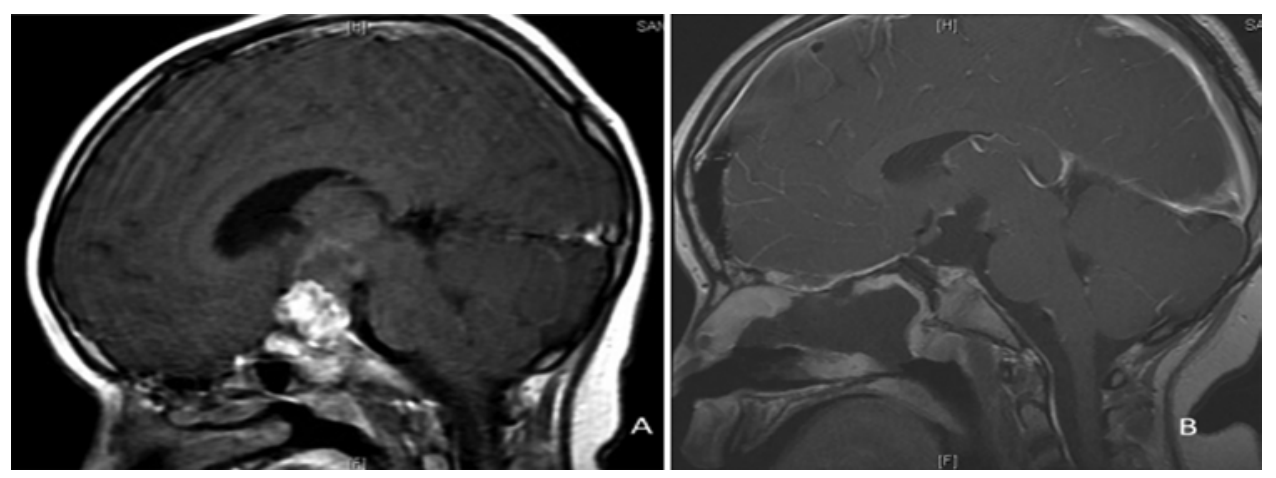

FIG. 1. Case 5. Resection of suprasellar craniopharyngioma. A: Preoperative sagittal contrast-enhanced MR image revealing a heterogeneously enhancing solid suprasellar space-occupying lesion (craniopharyngioma) with hypothalamic involvement, extending into the third ventricle. B: Postoperative MR image showing GTR of the tumor. 
TABLE 2. Extent of resection, vision, and academic outcomes

\begin{tabular}{ccccccl}
\hline Case No. & Pathology Subtype & FU (mos) & Extent of Resection & Hypothalamic Involvement & Postop Vision & Current Academic Status \\
\hline 1 & Adamantinomatous & 12 & STR & Yes & Worse & Back to school \\
\hline 2 & Adamantinomatous & 116 & STR & Yes & Worse & Not back to school \\
\hline 3 & Adamantinomatous & 40 & NTR & Yes & Stable & Poor academic performance \\
\hline 4 & Adamantinomatous & 63 & STR & Yes & Improved & Back to school (w/ ongoing rehabilitation) \\
\hline 5 & Adamantinomatous & 44 & GTR & Yes & Stable & Back to school \\
\hline 6 & Adamantinomatous & 15 & GTR & No & Worse & Back to school \\
\hline 7 & Adamantinomatous & 88 & GTR & No & Stable & Back to school \\
\hline 8 & Adamantinomatous & 64 & Biopsy & No & Stable & Back to school \\
\hline 10 & Adamantinomatous & 2 & NTR & Yes & Worse & Back to school \\
\hline 11 & Adamantinomatous & 4 & GTR & No & Improved & Back to school \\
\hline
\end{tabular}

$\mathrm{FU}=$ follow-up.

Preoperative BMI was recorded in all 11 patients, and it ranged from 14.34 to $34.28 \mathrm{~kg} / \mathrm{m}^{2}$ (mean $22.43 \mathrm{~kg} / \mathrm{m}^{2}$ ). One child was obese prior to surgery. At latest follow-up, when compared with their preoperative BMI status, 2 patients $(18 \%)$ had a $>9 \%$ increase and 4 patients $(37 \%)$ had a $>4 \%$ increase. Of the 2 patients who had a $>9 \%$ increase in their BMI, one underwent NTR and the other underwent STR, while the 4 patients with $>4 \%$ increase underwent GTR. Vision was stable or improved in $8(73 \%)$ of 11 patients.

Four patients had normal vision preoperatively. Of these, one patient's vision worsened postoperatively, while the remaining 3 had no change in ophthalmological status. Of the 7 patients who had visual deficits preoperatively (confirmed by formal ophthalmological testing), 3 improved postoperatively, 2 remain unchanged, and 2 worsened.

\section{Academic Status}

We checked with the patients' primary care physicians and the patients' parents to ascertain their current academic status. We confirmed if they had resumed backto-academic activities-i.e., kindergarten or school-and if they were in the appropriate class for their age. All 11 patients were back to academic activities-one was in a disability school with rehabilitation exercises but was in the class grade appropriate for age, while another was in a class grade low for age due to cognitive impairment.

\section{Nasal Symptoms}

Eight of the 11 patients did not complain of any nasal symptoms. One patient had anosmia that resolved about a year after surgery. One patient had some episodes of epistaxis postoperatively, and another patient complained of nasal discharge with associated hyposmia (which resolved a month after surgery).

\section{Recurrence and Adjuvant Treatment}

Recurrence was noted in 1 patient after a mean followup of 43 months. This patient had radiotherapy and repeat surgery; the patient had a prior resection before referral to our institution where GTR was presumably achieved. Five
(45\%) of the patients received postoperative radiotherapy, consisting of fractionated radiotherapy in 4 and proton beam radiotherapy in 1 . Of these cases, 4 were for residual tumor (NTR, STR, biopsy, and NTR) and 1 was for recurrent tumor (GTR). One patient with residual tumor had repeat surgery without adjuvant radiotherapy.

\section{Complications}

Complications occurred in $3(27 \%)$ of 11 patients. A CSF leak was reported in 1 patient (9\%). One patient required reexploration for evacuation of a hematoma 2 days

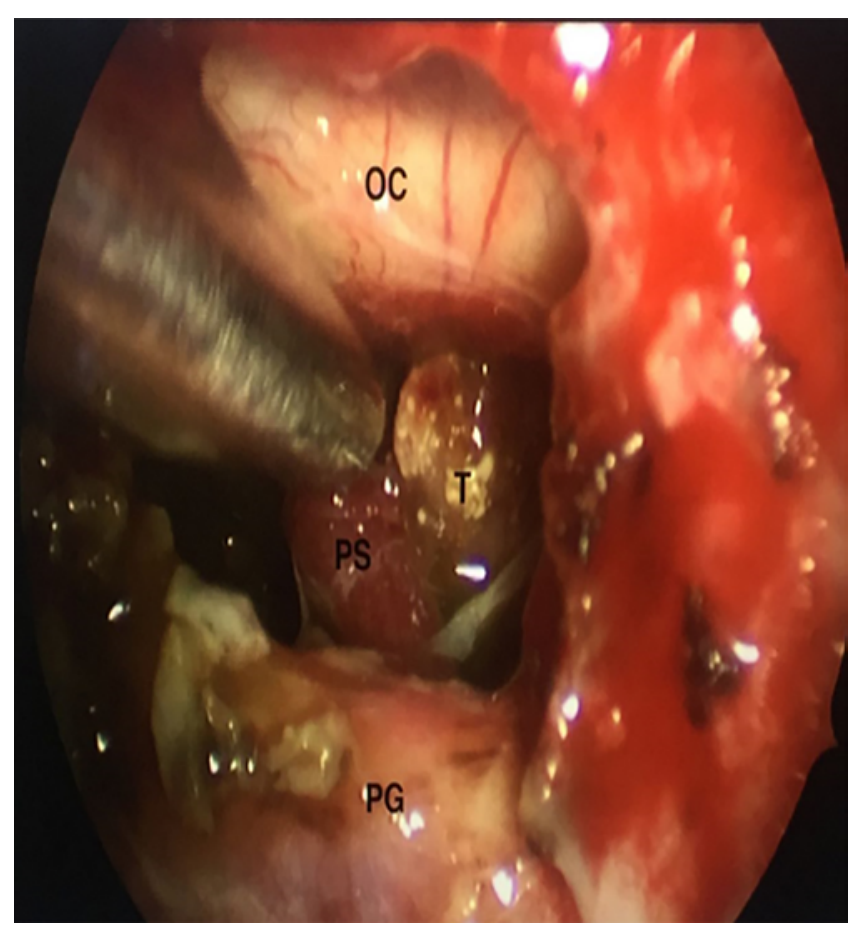

FIG. 2. Case 7. Intraoperative photograph demonstrating the optic chiasm $(\mathrm{OC})$ and the pituitary gland (PG). The craniopharyngioma tumor (T) and the pituitary stalk (PS) can be seen through the CPC. Figure is available in color online only. 
TABLE 3. Endocrine and shunt-dependency outcomes

\begin{tabular}{|c|c|c|c|c|c|c|}
\hline \multirow{2}{*}{$\begin{array}{l}\text { Case } \\
\text { No. }\end{array}$} & \multirow[b]{2}{*}{ Preop Dysfunction } & \multirow{2}{*}{$\begin{array}{c}\text { Most Recent } \\
\text { Hormonal Status }\end{array}$} & \multicolumn{2}{|c|}{ BMI } & \multirow[b]{2}{*}{ Intraop CSF Diversion } & \multirow{2}{*}{$\begin{array}{c}\text { Shunt } \\
\text { Dependency }\end{array}$} \\
\hline & & & Preop $\left(\mathrm{kg} / \mathrm{m}^{2}\right)$ & Postop Increase & & \\
\hline 1 & High PRL, low cortisol & Low cortisol, hypothyroidism & 18.2 & None & External ventricular drain & No \\
\hline 2 & $\begin{array}{l}\text { High PRL, low TSH, low } \\
\text { IGF-1, low cortisol }\end{array}$ & No change & 22.86 & None & Lumbar drain & No \\
\hline 3 & Normal & Hypocortisolemia, DI & 16.8 & $>9 \%$ & External ventricular drain & No \\
\hline 4 & High PRL & Low ACTH, low TSH & 25.31 & $>9 \%$ & Shunt & Yes \\
\hline 5 & Normal & Panhypopituitarism, DI & 24.61 & $>4 \%$ & Cystic fenestration \& lumbar drain & No \\
\hline 6 & Low IGF-1 & Panhypopituitarism, DI & 14.34 & None & Lumbar drain & No \\
\hline 7 & Low IGF-1, low TSH & Panhypopituitarism & 24.93 & $>4 \%$ & Lumbar drain & No \\
\hline 8 & Low IGF-1, high PRL & Panhypopituitarism, DI & 17.93 & $<4 \%$ & Cystic fenestration \& lumbar drain & No \\
\hline 9 & Normal & Panhypopituitarism, DI & 19.85 & None & Lumbar drain & No \\
\hline 10 & Low cortisol, low TSH & Hypocortisolemia, DI & 26.96 & $>4 \%$ & Lumbar drain & No \\
\hline 11 & High T3 & Panhypopituitarism, DI & 34.28 & $>4 \%$ & Lumbar drain & No \\
\hline
\end{tabular}

$\mathrm{ACTH}=$ adrenocorticotropic hormone; IGF-I = insulin-like growth factor-1; PRL = prolactin; $\mathrm{TSH}=$ thyroid stimulating hormone; $\mathrm{T} 3=$ triiodothyronine .

postoperatively after suffering acute left-sided visual loss. The visual impairment improved after surgery, although not back to its preoperative level. Two patients had major postoperative complications: One patient developed an infarct of the optic nerve with unilateral loss of vision, and the other developed an intracranial abscess around a fat graft, leading to an infarct in the basal ganglia and subsequent reoperation for removal of the graft.

\section{Discussion}

Neurosurgeons face unique challenges in treating pediatric craniopharyngiomas due to the anatomical constraints of the developing skull base as well as the importance of the surrounding structures for normal development. ${ }^{6}$ Given that these are benign tumors, curative therapy is optimal since multiple recurrences over a lifetime requiring repeated multimodality interventions can lead to devastating consequences with dramatic impact on quality of life. However, aggressive surgical therapy often leads to hypothalamic damage, which also can result in significant behavioral and developmental consequences. In the adult population, the view afforded by the extended endoscopic approaches, particularly of the walls of the hypothalamus, the pituitary stalk and its blood supply, and the inferior aspect of the chiasm, has led to improved outcomes in carefully selected craniopharyngioma cases. ${ }^{36}$ Whether these same advantages apply to the pediatric population is not clear. Retrospective reviews of the literature in this population are fraught with selection bias since patients who are chosen for craniotomy tend to have larger tumors with more visual loss and higher rates of increased intracranial pressure. ${ }^{15}$

The transsphenoidal approach has been applied to pediatric craniopharyngiomas but mostly to those with a sellar origin. It is estimated that roughly $50 \%-85 \%$ of pituitary craniopharyngiomas have sellar involvement, but the transphenoidal approach seems to be underutilized in this patient population, a situation thought to represent a lack of experience with this approach among pediatric neurosurgeons. ${ }^{26}$ Our paper adds significantly to the literature because the majority of reported pediatric craniopharyngiomas resected via a purely endonasal endoscopic transsphenoidal approach arise from within the sella. In the present article, we show the versatility of the EEA to also manage pediatric patients with purely suprasellar tumors. Moreover, prior papers have recommended using the endonasal transsphenoidal approach mostly for cystic tumors. ${ }^{19}$ However, we achieved a $40 \%$ GTR rate in cases of solid/mixed tumors and wish to emphasize the utility of this approach not only for cystic tumors but also for solid ones. The key to removing solid tumors is adequate instrumentation and the experience of the surgeon in performing bimanual endonasal sharp dissection. The extent of resection we achieved, $50 \%$, is in the midrange of resection percentages documented in prior reports, which span from $10 \%$ to $90 \%{ }^{9,14,18,34,37}$ However, this is not a reflection of the limitation of the approach. Indeed, our ability to assess intraoperative hypothalamic involvement using the endoscope is arguably superior to what can be achieved using the microscope. Since our center adheres to the philosophy of not removing tumor that invades the hypothalamus in the pediatric population, several of our cases had an NTR or STR based on an intentional intraoperative decision to leave tumor behind.

With respect to endocrine function, high rates of postoperative panhypopituitarism and DI are expected, particularly if GTR is the goal. ${ }^{23,24,28,47,59,60}$ Postoperative anterior pituitary deficiencies are found in roughly $67 \%$ of patients, and anywhere from $36 \%$ to $69 \%$ of patients experience DI, regardless of the operative approach. ${ }^{19,26}$ Our results are on par with those in the current literature, and the development of postoperative pituitary dysfunction likely has more to do with the intrinsic invasiveness of the tumor and the goals of surgery and less to do with the selected approach. Rates of visual improvement, on the other hand, tend to be higher following transsphenoidal resection of craniopharyngiomas than after open transcranial surgery in both the adult and pediatric age groups. ${ }^{19,31}$ Our data also point to higher rates of visual improvement than are seen 
with a craniotomy. We found a higher rate of visual deterioration than previously reported. In particular, one child completely lost vision unilaterally, due to a focal ischemic injury to one of the optic nerves. This was undoubtedly caused by inadvertent damage to a small perforator and is a reminder of the importance of preserving the vascular supply to the chiasm and nerve. The superior hypophyseal arteries supply both the stalk and the optic chiasm, and the surgeon must be careful to sacrifice only those branches feeding the stalk and tumor if required to achieve a GTR and not those supplying the chiasm.

The more devastating complication in the pediatric age group results from hypothalamic injury, which can cause a spectrum of dysfunction including hyperphagia, obesity, memory deficits, problems with social interaction, rage behavior, and sleep-wake cycle and thermoregulatory disturbances. ${ }^{16,47} \mathrm{New}$ obesity and hyperphagia are reported in approximately $35 \%$ of children after craniopharyngioma surgery, regardless of the approach. ${ }^{19,26}$ The devastating nature of these deficits has led many practitioners to recommend STR followed by radiation therapy in those patients with known hypothalamic invasion. ${ }^{57}$ Moreover, some authors recommend using the transsphenoidal approach only for subdiaphragmatic tumors or tumors with an enlarged or involved sella. ${ }^{19,26}$ We have shown that it is possible to use the EEA for a wide variety of tumors, some with purely suprasellar location and hypothalamic invasion, with a reasonable morbidity rate. While some patients underwent NTR or STR to avoid hypothalamic injury, in others a GTR was achieved despite radiographic evidence of hypothalamic injury. The decision to leave or remove tumor is difficult in such cases since some children with significant preoperative hypothalamic involvement may end up becoming obese, due to preexisting hypothalamic damage, regardless of the aggressiveness of the surgery. However, one advantage of the EEA is the surgeon can visualize the floor of the hypothalamus directly and determine the invasiveness based on direct observation. While roughly $18 \%$ of our patients did gain significant weight postoperatively, over $90 \%$ were back in school.

\section{Significance of Skull Base Development in Relation to Pediatric EEA}

Skull base compartments evolve continuously in the first 10 years of life and mold along with the anatomical structures in close proximity. ${ }^{5}$ The pneumatization process of the yet rudimental paranasal sinuses model skull base bone structures in a caudal-rostral pattern, while the sphenoid sinus pneumatization is a step-wise process following an anterior-posterior trend. ${ }^{36}$ All these make the EEA a challenge to perform when dealing with pediatric craniopharyngiomas..$^{444,49,62}$ Tatreau et al. ${ }^{58}$ and Scuderi et al. ${ }^{54}$ have shown that the pneumatization pattern follows a strict caudal-to-rostral pattern and lateral direction. The aeration of the sphenoid sinus is the direct determinant of the drilling distance and can help establish the best entry point to access the skull base. In children from age 0 to 10 years, more drilling is usually required. However, after age 11 , access to the parasellar area is more easily gained due to the lateral aeration. It should be emphasized that safe drilling can be achieved through the soft immature bone regardless of pneumatization level, especially when accessing lesions in the midline.

Another challenge in pediatric craniopharyngioma surgery is the distance between the top of the pituitary gland and the bottom of the optic chiasm. This CPC is critical to successful suprasellar surgery. We have already reported in a series of adults that the mean CPC is $10.1 \mathrm{~mm}$ (range 5.2-19.1 mm). ${ }^{7}$ We showed that the size of the CPC was irrelevant to our ability to remove tumors. Curiously, the mean CPC in our pediatric population was similar, which may explain why the EEA is successful at removing large suprasellar tumors, even in children.

\section{Limitations}

Several limitations exist in this study. It was a singlecenter series that involved a small group of patients studied in a retrospective fashion. This design had inherent bias and inaccuracies, and the small population precluded meaningful statistical analysis. The series also lacked preand postoperative neuropsychological or quality of life assessments. Several factors precluded these investigations, such as the emergency presentation(s) or insurance status and, hence, the reliance on academic performance as a metric of cognitive outcome.

\section{Conclusions}

Our data show the utility of the EEA in the pediatric population despite factors previously thought to be contraindications, including young age, prior surgery, conchal sinus configuration, suprasellar location, lesion size, and predominantly solid consistency. Our data also show that pediatric craniopharyngiomas remain challenging to treat and require a multidisciplinary approach.

\section{References}

1. Ali ZS, Bailey RL, Daniels LB, Vakhshori V, Lewis DJ, Hossain AT, et al: Comparative effectiveness of treatment options for pediatric craniopharyngiomas. J Neurosurg Pediatr 13:178-188, 2014

2. Ali ZS, Lang SS, Kamat AR, Adappa ND, Palmer JN, Storm $\mathrm{PB}$, et al: Suprasellar pediatric craniopharyngioma resection via endonasal endoscopic approach. Childs Nerv Syst 29:2065-2070, 2013

3. Bal E, Öge K, Berker M: Endoscopic endonasal transsphenoidal surgery, a reliable method for treating primary and recurrent/residual craniopharyngiomas: nine years of experience. World Neurosurg 94:375-385, 2016

4. Bartels U, Laperriere N, Bouffet E, Drake J: Intracystic therapies for cystic craniopharyngioma in childhood. Front Endocrinol (Lausanne) 3:39, 2012

5. Banu MA, Guerrero-Maldonado A, McCrea HJ, GarciaNavarro V, Souweidane MM, Anand VK, et al: Impact of skull base development on endonasal endoscopic surgical corridors. J Neurosurg Pediatr 13:155-169, 2014

6. Banu MA, Rathman A, Souweidane MM, Anand VK, Greenfield JP, Schwartz TH: Corridor-based endonasal endoscopic skull base surgery for pediatric skull base surgery with detailed radioanatomic measurements. Neurosurgery 10 (Suppl 2):273-293, 2014

7. Bulent Omay S, Almeida JP, Chen YN, Shetty SR, Liang B, Ni S, et al: Is the chiasm-pituitary corridor size important for achieving gross total resection during endonasal endoscopic 
resection of craniopharyngiomas? J Neurosurg [in press], 2017

8. Bunin GR, Surawicz TS, Witman PA, Preston-Martin S, Davis F, Bruner JM: The descriptive epidemiology of craniopharyngioma. J Neurosurg 89:547-551, 1998

9. Chakrabarti I, Amar AP, Couldwell W, Weiss MH: Longterm neurological, visual, and endocrine outcomes following transnasal resection of craniopharyngioma. J Neurosurg 102:650-657, 2005

10. Clark AJ, Cage TA, Aranda D, Parsa AT, Auguste KI, Gupta $\mathrm{N}$ : Treatment-related morbidity and the management of pediatric craniopharyngioma: a systematic review. J Neurosurg Pediatr 10:293-301, 2012

11. Clark AJ, Cage TA, Aranda D, Parsa AT, Sun PP, Auguste $\mathrm{KI}$, et al: A systematic review of the results of surgery and radiotherapy on tumor control for pediatric craniopharyngioma. Childs Nerv Syst 29:231-238, 2013

12. Cohen M, Bartels U, Branson H, Kulkarni AV, Hamilton J: Trends in treatment and outcomes of pediatric craniopharyngioma, 1975-2011. Neuro Oncol 15:767-774, 2013

13. Conger AR, Lucas J, Zada G, Schwartz TH, Cohen-Gadol AA: Endoscopic extended transsphenoidal resection of craniopharyngiomas: nuances of neurosurgical technique. Neurosurg Focus 37(4):E10, 2014

14. Couldwell WT, Weiss MH, Rabb C, Liu JK, Apfelbaum RI, Fukushima T: Variations on the standard transsphenoidal approach to the sellar region, with emphasis on the extended approaches and parasellar approaches: surgical experience in 105 cases. Neurosurgery 55:539-550, 2004

15. Crowley RK, Hamnvik OP, O’Sullivan EP, Behan LA, Smith D, Agha A, et al: Morbidity and mortality in patients with craniopharyngioma after surgery. Clin Endocrinol (Oxf) 73:516-521, 2010

16. De Vile CJ, Grant DB, Kendall BE, Neville BG, Stanhope R, Watkins KE, et al: Management of childhood craniopharyngioma: can the morbidity of radical surgery be predicted? J Neurosurg 85:73-81, 1996

17. Dhandapani S, Singh H, Negm HM, Cohen S, Souweidane $\mathrm{MM}$, Greenfield JP, et al: Endonasal endoscopic reoperation for residual or recurrent craniopharyngiomas. J Neurosurg 126:418-430, 2017

18. Dusick JR, Esposito F, Kelly DF, Cohan P, DeSalles A, Becker DP, et al: The extended direct endonasal transsphenoidal approach for nonadenomatous suprasellar tumors. J Neurosurg 102:832-841, 2005

19. Elliott RE, Jane JA Jr, Wisoff JH: Surgical management of craniopharyngiomas in children: meta-analysis and comparison of transcranial and transsphenoidal approaches. Neurosurgery 69:630-643, 2011

20. Fernandez-Miranda JC, Gardner PA, Snyderman CH, Devaney KO, Strojan P, Suárez C, et al: Craniopharyngioma: a pathologic, clinical, and surgical review. Head Neck 34:1036-1044, 2012

21. Fjalldal S, Holmer H, Rylander L, Elfving M, Ekman B, Osterberg K, et al: Hypothalamic involvement predicts cognitive performance and psychosocial health in long-term survivors of childhood craniopharyngioma. J Clin Endocrinol Metab 98:3253-3262, 2013

22. Garcia-Navarro V, Anand VK, Schwartz TH: Gasket seal closure for extended endonasal endoscopic skull base surgery: efficacy in a large case series. World Neurosurg 80:563-568, 2013

23. Hoffman HJ, De Silva M, Humphreys RP, Drake JM, Smith ML, Blaser SI: Aggressive surgical management of craniopharyngiomas in children. J Neurosurg 76:47-52, 1992

24. Honegger J, Buchfelder M, Fahlbusch R: Surgical treatment of craniopharyngiomas: endocrinological results. J Neurosurg 90:251-257, 1999

25. Im SH, Wang KC, Kim SK, Chung YN, Kim HS, Lee CH, et al: Transsphenoidal microsurgery for pediatric craniopharyngioma: special considerations regarding indications and method. Pediatr Neurosurg 39:97-103, 2003

26. Jane JA Jr, Prevedello DM, Alden TD, Laws ER Jr: The transsphenoidal resection of pediatric craniopharyngiomas: a case series. J Neurosurg Pediatr 5:49-60, 2010

27. Jeswani S, Nuño M, Wu A, Bonert V, Carmichael JD, Black $\mathrm{KL}$, et al: Comparative analysis of outcomes following craniotomy and expanded endoscopic endonasal transsphenoidal resection of craniopharyngioma and related tumors: a singleinstitution study. J Neurosurg 124:627-638, 2016

28. Kassam AB, Gardner PA, Snyderman CH, Carrau RL, Mintz AH, Prevedello DM: Expanded endonasal approach, a fully endoscopic transnasal approach for the resection of midline suprasellar craniopharyngiomas: a new classification based on the infundibulum. J Neurosurg 108:715-728, 2008

29. Kim SK, Wang KC, Shin SH, Choe G, Chi JG, Cho BK: Radical excision of pediatric craniopharyngioma: recurrence pattern and prognostic factors. Childs Nerv Syst 17:531-537, 2001

30. Kiran NA, Suri A, Kasliwal MK, Garg A, Ahmad FU, Mahapatra AK: Gross total excision of pediatric giant cystic craniopharyngioma with huge retroclival extension to the level of foramen magnum by anterior trans petrous approach: report of two cases and review of literature. Childs Nerv Syst 24:385-391, 2008

31. Komotar RJ, Starke RM, Raper DM, Anand VK, Schwartz TH: Endoscopic endonasal compared with microscopic transsphenoidal and open transcranial resection of craniopharyngiomas. World Neurosurg 77:329-341, 2012

32. Koutourousiou M, Gardner PA, Fernandez-Miranda JC, Tyler-Kabara EC, Wang EW, Snyderman CH: Endoscopic endonasal surgery for craniopharyngiomas: surgical outcome in 64 patients. J Neurosurg 119:1194-1207, 2013

33. Laufer I, Anand VK, Schwartz TH: Endoscopic, endonasal extended transsphenoidal, transplanum transtuberculum approach for resection of suprasellar lesions. J Neurosurg 106:400-406, 2007

34. Laws ER, Kanter AS, Jane JA Jr, Dumont AS: Extended transsphenoidal approach. J Neurosurg 102:825-828, 2005

35. Leng LZ, Brown S, Anand VK, Schwartz TH: Gasket-seal watertight closure in minimal access endoscopic cranial base surgery. Neurosurgery 62 (5 Suppl 2): ONSE342-ONSE343, 2008 (Abstract)

36. Leng LZ, Greenfield JP, Souweidane MM, Anand VK, Schwartz TH: Endoscopic, endonasal resection of craniopharyngiomas: analysis of outcome including extent of resection, cerebrospinal fluid leak, return to preoperative productivity, and body mass index. Neurosurgery 70:110124,2012

37. Maira G, Anile C, Albanese A, Cabezas D, Pardi F, Vignati $\mathrm{A}$ : The role of transsphenoidal surgery in the treatment of craniopharyngiomas. J Neurosurg 100:445-451, 2004

38. Mascarenhas L, Moshel YA, Bayad F, Szentirmai O, Salek AA, Leng LZ, et al: The transplanum transtuberculum approaches for suprasellar and sellar-suprasellar lesions: avoidance of cerebrospinal fluid leak and lessons learned. World Neurosurg 82:186-195, 2014

39. McCoul ED, Anand VK, Singh A, Nyquist GG, Schaberg MR, Schwartz TH: Long-term effectiveness of a reconstructive protocol using the nasoseptal flap after endoscopic skull base surgery. World Neurosurg 81:136-143, 2014

40. McCrea HJ, George E, Settler A, Schwartz TH, Greenfield JP: Pediatric suprasellar tumors. J Child Neurol 31:13671376, 2016

41. Mortini P, Losa M, Pozzobon G, Barzaghi R, Riva M, Acerno $\mathrm{S}$, et al: Neurosurgical treatment of craniopharyngioma in adults and children: early and long-term results in a large case series. J Neurosurg 114:1350-1359, 2011 
42. Moussazadeh N, Prabhu V, Bander ED, Cusic RC, Tsiouris AJ, Anand VK, et al: Endoscopic endonasal versus open transcranial resection of craniopharyngiomas: a casematched single-institution analysis. Neurosurg Focus 41(6):E7, 2016

43. Müller HL: Childhood craniopharyngioma. Pituitary 16:5667, 2013

44. Müller HL: Craniopharyngioma, in Fliers E, Korbonits M, Romijn JA (eds): Handbook of Clinical Neurology. Clinical Neuroendocrinology. Amsterdam: Elsevier, 2014, Vol 124, pp 235-253

45. Nyquist GG, Anand VK, Singh A, Schwartz TH: Janus flap: bilateral nasoseptal flaps for anterior skull base reconstruction. Otolaryngol Head Neck Surg 142:327-331, 2010

46. Placantonakis DG, Tabaee A, Anand VK, Hiltzik D, Schwartz TH: Safety of low-dose intrathecal fluorescein in endoscopic cranial base surgery. Neurosurgery 61 (3 Suppl):161-166, 2007

47. Puget S, Garnett M, Wray A, Grill J, Habrand JL, Bodaert N, et al: Pediatric craniopharyngiomas: classification and treatment according to the degree of hypothalamic involvement. J Neurosurg 106 (1 Suppl):3-12, 2007

48. Raza SM, Banu MA, Donaldson A, Patel KS, Anand VK, Schwartz TH: Sensitivity and specificity of intrathecal fluorescein and white light excitation for detecting intraoperative cerebrospinal fluid leak in endoscopic skull base surgery: a prospective study. J Neurosurg 124:621-626, 2016

49. Reddy GD, Hansen D, Patel A, Lin Y, Jea A, Lam S: Treatment options for pediatric craniopharyngioma. Surg Neurol Int 7 (Suppl 6):S174-S178, 2016

50. Rigante M, Massimi L, Parrilla C, Galli J, Caldarelli M, Di Rocco C, et al: Endoscopic transsphenoidal approach versus microscopic approach in children. Int J Pediatr Otorhinolaryngol 75:1132-1136, 2011

51. Sankhla SK, Jayashankar N, Khan GM: Extended endoscopic endonasal transsphenoidal approach for retrochiasmatic craniopharyngioma: Surgical technique and results. J Pediatr Neurosci 10:308-316, 2015

52. Schwartz TH, Anand VK: The endoscopic endonasal transsphenoidal approach to the suprasellar cistern. Clin Neurosurg 54:226-235, 2007

53. Schwartz TH, Fraser JF, Brown S, Tabaee A, Kacker A, Anand VK: Endoscopic cranial base surgery: classification of operative approaches. Neurosurgery 62:991-1005, 2008

54. Scuderi AJ, Harnsberger HR, Boyer RS: Pneumatization of the paranasal sinuses: normal features of importance to the accurate interpretation of CT scans and MR images. AJR Am J Roentgenol 160:1101-1104, 1993

55. Shah RN, Surowitz JB, Patel MR, Huang BY, Snyderman $\mathrm{CH}$, Carrau RL, et al: Endoscopic pedicled nasoseptal flap reconstruction for pediatric skull base defects. Laryngoscope 119:1067-1075, 2009
56. Stefko ST, Snyderman C, Fernandez-Miranda J, Tyler-Kabara E, Wang E, Bodily L, et al: Visual outcomes after endoscopic endonasal approach for craniopharyngioma: the Pittsburgh experience. J Neurol Surg B Skull Base 77:326-332, 2016

57. Tabaee A, Placantonakis DG, Schwartz TH, Anand VK Intrathecal fluorescein in endoscopic skull base surgery. Otolaryngol Head Neck Surg 137:316-320, 2007

58. Tatreau JR, Patel MR, Shah RN, McKinney KA, Wheless SA, Senior BA, et al: Anatomical considerations for endoscopic endonasal skull base surgery in pediatric patients. Laryngoscope 120:1730-1737, 2010

59. Van Effenterre R, Boch AL: Craniopharyngioma in adults and children: a study of 122 surgical cases. J Neurosurg 97:3-11, 2002

60. Weiner HL, Wisoff JH, Rosenberg ME, Kupersmith MJ, Cohen H, Zagzag D, et al: Craniopharyngiomas: a clinicopathological analysis of factors predictive of recurrence and functional outcome. Neurosurgery 35:1001-1011, 1994

61. Zada G, Kintz N, Pulido M, Amezcua L: Prevalence of neurobehavioral, social, and emotional dysfunction in patients treated for childhood craniopharyngioma: a systematic literature review. PLoS One 8:e76562, 2013

62. Zhang S, Fang Y, Cai BW, Xu JG, You C: Intracystic bleomycin for cystic craniopharyngiomas in children. Cochrane Database Syst Rev 7:CD008890, 2016

63. Zoicas F, Schöfl C: Craniopharyngioma in adults. Front Endocrinol (Lausanne) 3:46, 2012

\section{Disclosures}

Dr. Souweidane is a consultant for Aesculap.

\section{Author Contributions}

Conception and design: Schwartz, Alalade, Ogando-Rivas, Boatey. Acquisition of data: Schwartz, Alalade, Ogando-Rivas, Boatey, Souweidane, Anand. Analysis and interpretation of data: Alalade, Ogando-Rivas, Boatey. Drafting the article: Schwartz, Alalade, Ogando-Rivas, Boatey. Critically revising the article: Schwartz, Alalade, Greenfield. Reviewed submitted version of manuscript: Schwartz, Greenfield. Approved the final version of the manuscript on behalf of all authors: Schwartz. Operating surgeon: Schwartz, Souweidane, Anand, Greenfield.

\section{Correspondence}

Theodore H. Schwartz, Department of Neurosurgery, Weill Cornell Medical College, 525 East 68th St., Box 99, New York, NY 10065. email: schwarh@med.cornell.edu. 